members Major-Gen. Sir F. Maurice, Brig.-Gen. E. L. Spears, Prof. A. Zimmern, Prof. N. J. Baker, Prof. H. V. Temperley, President N. B. Butler, M. Nicolas Politis. This Committee will advise upon research work on the principles of international relations, questions of international justice, law and equity, and problems of international security. The publications of the Institute will include monographs and a quarterly review in English, German and French, and preparations are being made for the publication of a yearbook. The work is largely carried out by means of circular letters, but it is also proposed to hold conferences twice a year in different centres. A series of fortnightly 'round table' discussions has also been initiated.

\section{Training for Industrial Management}

IN a report entitled 'Three Years' Experience and Results in the Training of Scientific Men for Industrial Management" (57 Gordon Square, London, W.C.1), Mr. W. R. Dunlop describes the work which he has carried out in providing facilities for training in this subject on the lines of personal and individual tuition, and more recently by correspondence. The courses, he explains, were not undertaken in the expectation of obtaining spectacular results; but experience has shown that scientific and technical men are definitely interested, and that those who have taken full advantage of the training have derived substantial benefit in one way or another. A difficulty has been to get something out of the students as well as putting something in. It has been hard to make chemists in particular understand that management is not a subject but an activity, and that action, energy and initiative as well as passive absorption of knowledge must be demonstrated in a course of training. Chemists in some cases appear to suffer from an 'inferiority complex' in regard to expressing opinions on matters outside their immediate province, while on the other hand many engineers, especially mechanical engineers, tend to go to the other extreme.

\section{Public Health in British Colonies in 1932}

THE fourth Supplement to the Tropical Diseases Bulletin, December, 1934, contains summaries by Dr. Harold Scott of medical and sanitary reports relating to the year 1932 from British colonies, protectorates, and dependencies. The summaries give for each country the year's record of vital statistics, maternity and child welfare work, school hygiene, general sanitation, housing and town planning, etc., followed by particulars of the tropical diseases occurring in them, and the measures taken locally to combat them. The records show, on the whole, that in spite of retrenchments of medical staffs and curtailment of expenditure on public health services, the general health of the English communities has been well maintained, and no appreciable increase of sickness has occurred in the native communities. Retrenchment has had the effect of bringing to the fore the question of the local training of natives for medical duties. In the Gold Coast, a scheme for the training of nurse-dispensers has been instituted, and elsewhere medical schools exist where native prac. titioners have been successfully trained.

\section{Ross Institute Industrial Advisory Committee}

A meeting of this Committee, at which the chairman, Mr. G. H. Masefield, presided, was held on January 29 last at the rooms of the Indian Tea Association. The meeting was addressed by Sir Malcolm Watson, who described some of the antimalarial measures that have been undertaken in Southern Rhodesia, Beira and some of the Gold Coast mines, by Mr. A. Wigglesworth, who raised the question of malarial conditions on sisal estates, and by others. Dr. Ramsay, of the Ross Institute in India, mentioned the 'eye fly', which is not only a nuisance but also a danger, as it transmits catarrhal conjunctivitis, and against which no effective measures are known except protection by means of wire gauze spectacles. Sir Malcolm Watson directed attention to a booklet on the prevention of malaria which is distributed free to those residing in, or proceeding to, the tropics. The Ross Institute, which is amalgamated with the London School of Hygiene and Tropical Medicine, is the medium through which industries in the tropics keep in touch with the work of the combined bodies and seek advice, and some $£ 15,000$ are required annually from voluntary subscriptions for propaganda work and appeals.

\section{Microscopes and Accessory Apparatus}

IN the 1934 edition of the catalogue issued by Messrs. Carl Zeiss (London), Ltd. (37 Mortimer Street, London, W.1), after an excellent introduction upon the theory of the microscope, the series of microscope stands manufactured is described. The design of the microscope stand has substantially altered in recent years, and the usual form now adopted consists of a broad base which supports a one-piece limb for carrying the illuminating system, the stage and the tube. This one-piece limb is in the form of a segment of a circle with a deep central recess. This recess serves as a handle, and provides ample range for a large stage. Another convenient modern device is the inclined tube, single or binocular, which can be fitted to most of the models, in some of which the fine-adjustment head is located in the tilting axis. A large range of Huygenian and compensating eyepieces, and achromatic, fluorite and apochromatic objectives, are manufactured. Petrological and other types of special stands, magnifiers, hæmacytometers, micrometers, micro-manipulator, photomicrographic cameras and other accessory apparatus are also listed.

\section{Research on Bird Migration}

THE German Government has issued an announcement referring to the work of the German bird migration research stations-in Heligoland and at Rossitten-where rings are attached every year to the feet of more than 160,000 migratory birds. The rings are inscribed with identification numbers and with the address of one or other of the stations"Vogelwarte Helgoland" or "Vogelwarte Rossitten" 